\title{
Leisure, income inequality and the Veblen effect: cross-national analysis of leisure time and sport and cultural activity
}

\author{
Published in Leisure Studies, 2015: http://dx.doi.org/10.1080/02614367.2015.1036104
}

\section{Introduction}

This paper was prompted by the work of Richard Wilkinson and Kate Pickett, published in their book, The Spirit Level: Why More Equal Societies Almost Always do Better (2009), in which they used cross-national secondary data from the United Nations and other sources to make the case that the more equal the distribution of income in a country the more favourable are the scores on a range of indicators of human well-being in areas such as: trust (of neighbours, etc.); life-expectancy; infant mortality; obesity (adults and children); mental illness; educational performance; and a composite Index of Health and Social Problems. Wilkinson and Pickett noted that international surveys show that increasing national longevity and happiness indicators are associated with increasing average income up to a certain level, but that above an annual national income per head of about \$US20K (2005 prices), the relationship disappears (Wilkinson \& Pickett, 2009: 9), suggesting that factors other than absolute income are at play. In their study they therefore concentrated on the 25 countries with the highest annual per capita national incomes ${ }^{i}$. Income inequality was measured by the ratio of the share of total income of the top 20 per cent of households to that of the bottom 20 per cent, a measure referred to as S80/S20. The Spirit Level is written in a semi-popular style and a notable feature is the illustration of the relationships between income inequality and single well-being measures using scatter-plots with superimposed regression lines, an example of which is shown in Figure 1. The cumulative effect of a series of some 30 of such graphs throughout the book is a compelling one. They also claimed that, in more equal societies, all income groups enjoy measurably enhanced well-being, not just the poorer groups.

Figure 1. Income inequality and trust in the community: international comparisons

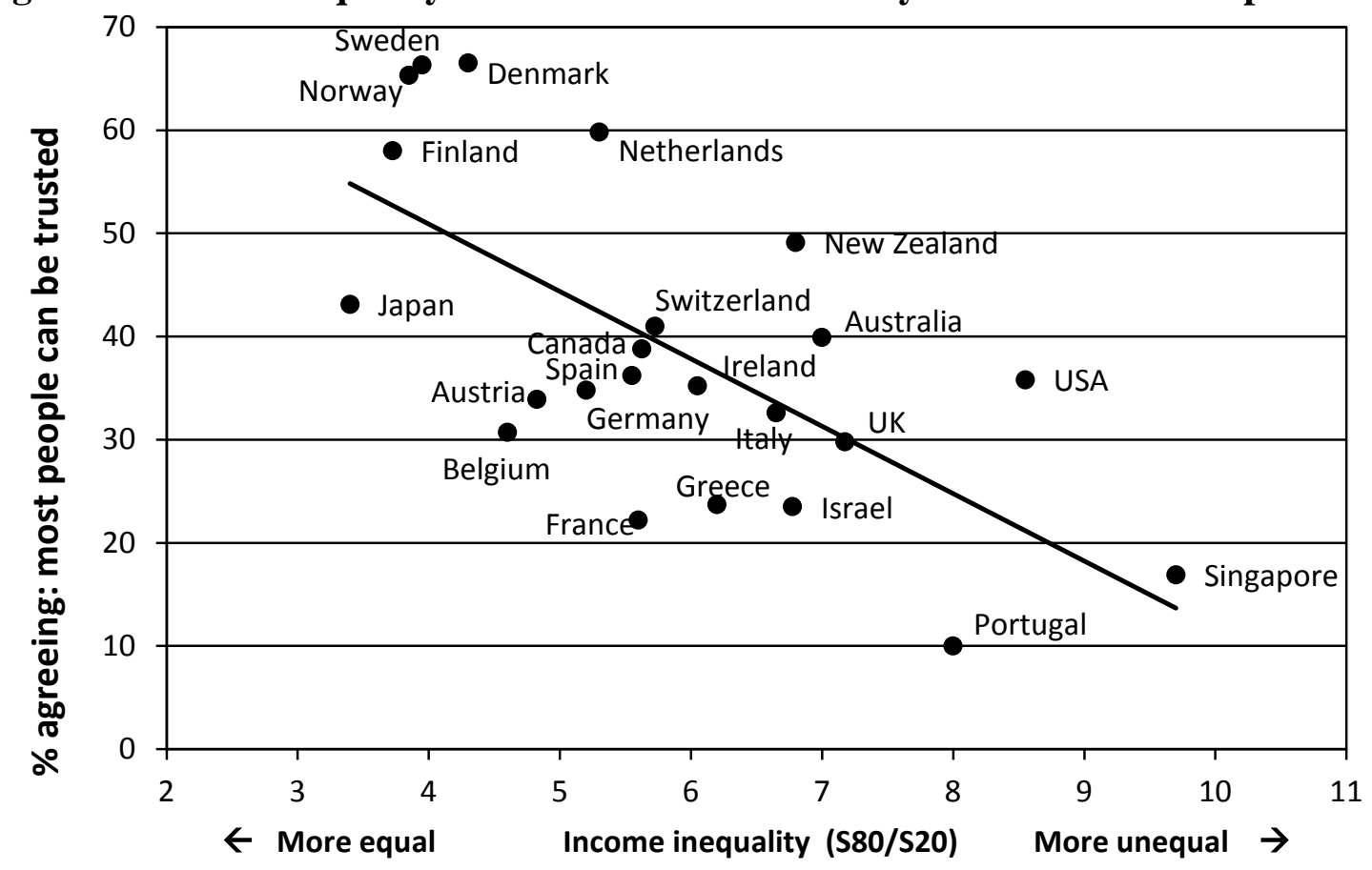

Source: Reconstruction of Spirit Level Figure 4.1 (Wilkinson \& Pickett, 2009: 52)

$\mathrm{R}^{2}=0.44$ (not shown in the original). 
The Spirit Level does not include leisure participation patterns among its indicators of human well-being, although it does refer to obesity, which has a connection with exercise, to illegal/ recreational drug use and, briefly, to hours of work. Given that leisure time and leisure participation are widely accepted as being associated with human well-being (Haworth, 1997), the question therefore arises as to whether there is also a relationship between leisure indicators and income inequality. It is this question which is addressed in this paper.

The Spirit Level is focussed on health and other well-being factors, and leisure activity can be related to such concerns, both negatively (e.g. excessive consumption of recreational drugs - Parker et al., 1998) and positively (e.g. sport or cultural activity - Cuypers, Krokstad \& Holmen, 2012). While public policy and trades union campaigns in the 1960s and '70s supported increased leisure time through reductions in working hours and increased holidays, this issue is no longer to the fore, although numerous groups support similar goals under the banner of 'work-life balance' (Veal, 2012). Positive links between specific types of leisure activity and quality of life have often been the basis of public policy (Jackson, 2006), as exemplified by a British Labour government of the 1970s which declared that provision for recreation should be seen as 'part of the general fabric of the social services' (Department of the Environment, 1975: 1). A later government declared that cultural services, including sport, contributed to the aims of government by 'tackling social exclusion; encouraging healthier lifestyles; providing opportunities for voluntary and community activity; sparking urban and rural regeneration; or stimulating a commitment to lifelong learning, as well as enriching people's lives' (Department for Culture, Media and Sport, 1999: 3)

Wilkinson and Pickett (2009: 27) stipulate that, on the basis of their observations, for a factor to be considered within their analytical framework it should have a strong withincountry 'social gradient'. Such gradients are a well-established feature of various forms of leisure behaviour, particularly those promoted and supported by the state, such as participation in sport and the arts. From its beginnings the field of leisure studies has addressed social inequality, with the early major national surveys clearly pointing to significantly higher participation levels among higher income/social class groups (ORRRC, 1962: 12-13, 28; BTA/ University of Keele, 1967: 6, 76). While these patterns continue today (e.g. Sport England, 2013; ABS, 2011; Roberts, 2013), in more recent times, partly as a result of the New Labour agenda in Britain in the period 1997-2010, academic and policy considerations of inequality have tended to concentrate on the idea of social exclusion/ inclusion, related to such factors as ethnicity, gender and disability, rather than income/class (e.g. Belfiore, 2002; Coalter, 2013; Collins, 2003; Liu, 2009; Lusted, 2013; Sport England, 2004). Leisure has, therefore, been involved with inequality-related policy debates in one form or another for decades, so it would seem only appropriate that it be brought into the debate sparked by The Spirit Level and that, if income inequality is a relevant factor, this variable be introduced into leisure-related policy discourses.

Traditionally, various forms of economic inequality have been seen as a moral or political issue. Political ideologies of the left argue for a more equal society on the grounds of social justice, while those of the right argue against generous redistributive welfare payments and high levels of taxation of the rich, insisting that the rewards and incentives offered by significant income differentials are a feature of free societies and essential for the efficient and effective operation of the market system (e.g. Friedman and Friedman, 1979). The resultant faster economic growth, it is argued, benefits all. This stance has recently come under attack as deficient even in its own terms. For example, the Economist (2012: 14) has observed: 'inequality has reached a stage where it can be inefficient and bad for growth' while, in The Price of Inequality, Joseph Stiglitz (2013) argues that the low taxation/small government policies introduced by the United States and other Western governments since 
the 1980s, while being designed to boost economic growth, have resulted in the opposite. Skidelsky and Skidelsky (2012: 194) point to the failure of Western capitalism, at least since the 1980s, to deliver the dividends of economic growth to the mass of workers, particularly in the United States. The World Economic Forum (2014) identify 'severe income disparity' as one of the ten most serious 'global risk factors' and Thomas Picketty (2014) has established that long-term trends towards greater inequality of wealth threaten the stability of industrial economies.

Arguably, a key reason for The Spirit Level attracting the attention which it has, is that, in focusing on income distribution, it is dealing with policy levers which are already available to politicians in all wealthy countries and are a constant focus of political discussion.

However, in considering social inequality, or stratification, social theorists have traditionally tended to focus on class or status. Such analyses have been perceived as being of immediate policy relevance, since political divides in Western democracies were traditionally along class lines, even though policy administration, when not based on universal access, has typically been based on the narrower criterion of income (e.g. allocation of public housing, means tests for higher education grants). In recent years, as noted above, the focus has tended to be on social inclusion/exclusion. Policies to achieve social inclusion in the leisure sector are invariably complex, typically involving local pilot programmes, with national agencies often struggling with the process of policy formulation, implementation and evaluation , limited roll-outs and uncertain outcomes (Belfiore, 2002; Centre for Leisure and Sport Research, 2002; Collins, 2003). By contrast, income distribution is at the core of national government policy, with policy levers and outcomes which are familiar to decision-makers.

The Spirit Level has not been without its critics, most notably Goldthorpe (2010), Saunders (2010), Snowdon (2010a), Sanandaji, Malm and Sanandaji (2010) and Runciman (2009). The criticisms relate to empirical and theoretical validity of the analysis but also to issues of ideology and politics. The political implications of The Spirit Level are clear. A substantial part of the book is devoted to discussing the need for a transformation of unequal Western societies (Wilkinson \& Pickett, 2009: 231). Furthermore, the Equality Trust has been established in the UK to pursue this political agenda (www.equalitytrust. org.uk). The significance of the book's message for the Left of politics is highlighted by the fact that the most detailed critiques of The Spirit Level have been published by right-wing British 'think tanks', the Policy Exchange and the Democracy Institute, and the Taxpayers' Alliance which lobbies in favour of reduced taxation. One of the critics, Saunders (2010: 9), observes: 'The Spirit Level has attracted many enthusiastic plaudits among left-wing commentators since its publication in 2009. The reason is that it appears to offer 'scientific' validation of their ideological commitment to income levelling'. The sub-title of Snowdon's (2010a) critical book is Fact-checking the Left's New Theory of Everything and he observes that Wilkinson and Pickett's agenda calls for 'nothing less than the dismantling of the free market and an unprecedented shift of power from the individual to the state' with the market system 'jettisoned in favour of rationing and state ownership' (p. 145). Sanandaji et al. (2010: 27), from the Taxpayers' Alliance, conclude their critique with the statement: 'The authors' ability to package a wide range of social ills under one cause is bound to be politically attractive, particularly to politicians who are of the redistributive mindset already. ... [However] ... Policy makers need to be aware of the fact that The Spirit Level is not a reliable book based on objective science'. Wilkinson and Pickett's (2010b: 273-298) rebuttal of their critics, included in a postscript to the 2010, paperback, edition of the book, bears the title: 'Research Meets Politics'. They compare the attacks on their research with similar attacks on research identifying links between tobacco and cancer ${ }^{\mathrm{ii}}$ and more recently between human-induced carbon dioxide emissions and climate change (Oreskes \& Conway, 2010). 
These claims and counter-claims concern, in part, the empirical validity of Wilkinson and Picket's work. However, even if found to be valid, or correctable, statistical correlation as presented by Wilkinson and Picket does not necessarily indicate causality. They do, therefore, offer theoretical explanations for the empirical relationships found which have also been subject to debate. Following discussion of aspects of empirical validity, these theoretical/explanatory issues are examined below.

\section{Empirical validity}

The critics' concerns regarding empirical validity of Wilkinson and Pickett's work should be given some consideration since, if it lacks empirical validity, there would be little point in seeking a theoretical explanation for the findings. Furthermore, pursuing leisure-related analysis using similar methodology would only be worthwhile if the validity issues could be successfully addressed.

Saunders (2010) and Snowdon (2010a) level a number of accusations at Wilkinson and Pickett. First, they accuse them of 'cherry-picking' both countries and well-being indicators which suit their arguments. Second, they claim that the phenomenon of statistical 'outliers' in the data is ignored, and that when these are excluded from the analysis, the overall thesis is undermined. Third, it is claimed that considering only income inequality is to ignore other variables, such as absolute income level, ethnic composition of populations and distinctive national or regional cultures, which often provide a higher level of statistical explanation of variation in welfare measures and/or negate the effect of income inequality when controlled for. Fourth, Wilkinson and Pickett fail to test their thesis in relation to change over time, as opposed to cross-nationally. Last, they are accused of cherry-picking the existing literature on income inequality, ignoring sources which do not support their thesis and giving a false impression of consensus concerning the significance of income inequality, particularly in relation to health. Other critics include Goldthorpe (2010), who argues that a single economic measure, income inequality, is incapable of accounting for the complexity of social inequality in society and that Wilkinson and Pickett fail to address or understand the respective natures of class and status. Runciman (2009) argues that, in basing their analyses on average indicators for whole nations, Wilkinson and Pickett are guilty of 'fudging' the question as to whether or not, in more equal societies, all income groups do, in fact, do better, since higher well-being scores found in more equal societies could simply be the result of the improved scores of people at the bottom. Many would argue that this is in itself beneficial, but Wilkinson and Pickett make much of their claim that people at all income levels benefit from living in more equal societies.

Wilkinson and Pickett (2010a, 2010b: 273-290) have defended their work against the claims of the critics, although this defence has itself been challenged (Snowdon, 2010b, 2010c). The level of controversy has been intense, leading Wilkinson and Pickett to declare that they will, in future, respond only to criticism published in peer-reviewed journals (Jump, 2010). They have not, therefore, responded publicly to Sanandaji et al.'s (2010) more recent critique.

In summary, the empirical validity of the study of the relationship between income inequality and well-being variables, particularly health, is contested. However, in any further study, it should be possible to take account of some of the criticisms which have been raised, particularly: the choice of countries; the treatment of outliers; the role of national values/ culture; the within-country distribution of well-being indicators; and the measurement of income-inequality. Other issues arise from the theoretical discussion below. 


\section{Theoretical explanations}

Three types of theoretical proposition have been put forward to explain the relationship between income inequality and measures of well-being across countries: 1 . social statusrelated propositions; 2 . resource-related or neo-materialistic factors; and 3. differing national cultures ,traditions or value systems. These propositions are reviewed below and the implications for extension of the Spirit Level mode of analysis to the leisure domain are considered.

\section{Social status-related propositions}

Social status-related propositions consider the ways in which income inequality operates in the context of status-related hierarchical systems to bring about undesirable outcomes for social well-being. This type of explanation is favoured by Wilkinson and Pickett, who state that high levels of economic inequality are associated with broader patterns of social inequality which are reflected in conditions such as low levels of trust among fellow citizens, lack of social connections and community feeling and high levels of status anxiety. This in turn can lead to psychological stress, high levels of anti-social behaviour and limited social engagement. While it is widely claimed that people strive to 'keep up' not just with others in their own social world but with those above them in social and occupational status and income, and/or to keep ahead of those seen as being below them, Wilkinson and Pickett go further, in arguing that income and wealth distribution in a nation as a whole can be a cause of stress and negative feelings, throughout the social hierarchy:

Social inequality seems to heighten people's social evaluation anxieties by increasing the importance of social status. Instead of accepting each other as equals on the basis of our common humanity as we might in more equal settings, getting the measure of each other becomes more important as status differences widen. ... If inequalities are bigger, so that some people seem to count for almost everything and others for practically nothing, where each of us is placed becomes more important. Greater inequality is likely to be accompanied by increased status competition and increases in status anxiety. (Wilkinson and Pickett, 2009: 43-44)

This, they argue, explains why increased income inequality results in people being subject to stress-related illness. However, in The Spirit Level and their earlier review of the epidemiological evidence on the relationship between income inequality and health, Wilkinson and Pickett (2006) do not go beyond aggregate correlational analysis and so do not provide direct evidence of the status anxiety mechanism actually at work - a gap in their research pointed out by Goldthorpe (2010), Saunders (2010) and Lancee and Van der Werfhorst (2011: 34). Furthermore, as Elias and Dunning (1986: 93) point out, that tensions are invariably and universally negative experiences to be avoided or relieved is an assumption which has not been subject to systematic empirical testing: clearly, some individuals, groups, and even whole societies, would seem to relish the excitement and challenges of a competitive environment, both in work and play (see also De Botton, 2004: 302).

Theories of stratification, ranging from those of Veblen (1899/1970) to Bourdieu (1984), are a significant feature of leisure theory. Veblen described a process involving conspicuous leisure and consumption and the setting of canons of taste on the part of the wealthy leisure classes, which members of lower classes seek to emulate (Veblen, 1899/1970: 68-70) - a process now referred to as the 'Veblen effect' (Bagwell \& Bernheim, 1996). However, while he saw this process as unjust, invidious and wasteful, he did not explore wider implications for personal well-being. Bourdieu saw each class/occupational group as 
establishing its own distinctive set of tastes and values ('habitus') and corresponding patterns of consumption and leisure behaviour (lifestyle) which reinforce class status and boundaries. However, Bourdieu did not explicitly explore the wider consequences of this, in terms of general well-being throughout the class system; indeed, he concentrated mostly on the process as it operated among the managerial and professional classes.

Juliet Schor (1998: 3-4), on the other hand, is explicit about the negative consequences of the materialist, 'work-and-spend', consumerist status system which she observes in contemporary America, including personal stress, working excessively long hours to the neglect of other life domains and impacts on the environment. While she outlines the contradictions and futilities which permeate the process, she also seeks to explain why it nevertheless persists. In a market economy, with its emphasis on growth and innovation, resulting in rising incomes, at least for some: 'As long as a few fashion-minded or highly consumerist households take on the role of innovators, spending their increased income on new, better, or more consumer items, the impact of their consumption ripples through the system. Marketing and advertising accelerate the process' (Schor, 1998: 100), and Veblenesque emulation completes it.

Mainstream economists also have a perspective on the status-related explanation. Bowles and Park (2005) ${ }^{\mathrm{iii}}$ posit that, if the Veblen effect is in operation, variations in consumption levels will be related not to individuals' own incomes but to those of better off groups. They examine the relationship between income inequality (the ratio of the income cut-off level of the top 10 per cent earnings group to the overall median income, or P90/P50), and working hours (as an average indicator of income and hence consumption), finding a significant positive relationship for North America and ten European countries. They then develop the model using a number of additional variables. The model suggests that people work longer hours than they would if they were to take account only of their own incomes, so the result is sub-optimal, or a case of market failure, meriting government intervention to achieve more equality. Robert Frank (2005, 2006) refers to this form of market failure as the existence of 'positional externalities' and argues that, in the United States, 'the welfare losses from positional externalities are enormous, easily hundreds of billions of dollars a year or more' (Frank, 2006: 450). He argues for the use of consumption taxation measures to ameliorate their effects, although this is challenged by others (Kashden \& Klein, 2006).

In summary, the actual social-psychological processes underlying social status-related propositions remain under-researched, but economic frameworks, based on the Veblen effect and concerned with sub-optimal work/ leisure/consumption outcomes, appear to have a stronger empirical and theoretical basis. The analysis of Bowles and Park (2005) also raises the issue of the most appropriate measure of income inequality.

\section{Resource-related/neo-materialistic propositions}

Resource-related or neo-materialistic propositions argue that one of the features of more equal societies is that they seek to ameliorate the effects of poverty not only by direct transfer payments but also through the use of public expenditure to enhance levels of provision of, and/or access to, facilities and services. Conversely, in societies in which this equalising process is less developed, the poor in particular will not only have lower incomes but also reduced well-being outcomes as a result of reduced access to publicly supported services. Since the well-off have the means to buy services in the private market when they are not available via the public sector, it might be expected that this service-provision process would affect only the poorer sections of the community, but indirect effects and 'public good' effects can benefit all income groups. Indeed, it has often been suggested that the well-off take particular advantage of publicly provided/subsidised leisure services (e.g. Howard \& Crompton, 1984; Roberts, 2004: 50). 
Wilkinson and Pickett (2010b: 80-81, 184) do not favour this explanation because, they argue, in some countries (e.g. Japan) relative income equality is not the result of government actions but is an innate feature of the labour market. They also reject it on specific empirical grounds, claiming that public social expenditure is 'entirely unrelated' to their composite Index of Health and Social Problems (p. 184); and 'there is no relationship between health care expenditure and life expectancy' (p. 81). They also point out that public social expenditure can be high in some areas not only because of the provision of positive services but also because of the need to deal with the negative social consequences of a lack of services.

While exploration of the resource-related/ neo-materialistic thesis would make sense in a sector such as leisure, the lack of internationally comparable data on public leisurerelated expenditure is a practical barrier.

\section{Culture, tradition, values}

While Wilkinson and Pickett see income inequality as the independent variable, which is causally linked to a range of negative well-being outcomes, this begs the question: why do some societies have more unequal income distribution systems than others in the first place? For five of the 14 well-being variables addressed in The Spirit Level, Saunders' (2010) reanalysis relies on excluding the four Scandinavian countries, noting their distinctive egalitarian culture and polity. In one case he excludes both the Scandinavian and 'Anglo' countries on the grounds that both groups are culturally distinctive, compared with the rest of the economically developed world. With these groups of countries excluded, some of the significant statistical relationships between income inequality and well-being indicators disappear, leading to the suggestion that such relationships are significant only in countries with particular distinctive cultures. Wilkinson and Pickett (2010b: 282-3) respond that some countries with similar cultural traditions (e.g. Spain and Portugal) have very different wellbeing outcomes, while very different countries (e.g. Japan and Sweden) have similar outcomes. Furthermore, they argue, given that national cultures vary in so many ways, it seems unlikely that a measure of cultural distinctiveness could be found which would explain variations in well-being measures across the board as income inequality does.

It could, however, be argued that, among Western countries at least, the various cultures/ traditions are not alien from one another but lie along recognisable political/religious dimensions (conservative/ social democratic, protestant/catholic, etc.) and countries are capable of movement back and forth along those dimensions over time. So the differences can be seen as indicative of variables within a common population rather than radically different populations. Gratton et al. (2011), in an analysis of sport and income inequality using 2004 Eurobarometer data, note the differences between northern, middle and southern/ Mediterranean European countries, pointing in the direction of including 'country type' as a variable in the cross-national analysis rather than a reason for abandoning it. It is possible that this could be approached on a systematic basis in multivariate cross-national studies of inequality (e.g. Inglehart \& Baker, 2000; Goodin et al., 2008).

Since leisure behaviour patterns are likely to be influenced by cultural values, it would seem appropriate to explore this dimension in analysis of income inequality and leisure.

\section{Income inequality and leisure}

Some 40 years ago, Joffre Dumazedier (1974: 187-205) argued in favour of the use of the cross-national 'comparative method' to study possible leisure trends, suggesting that 'tomorrow's history may, under some conditions, be deduced not from yesterday's but from the contemporary history of another society'. In this regard, he drew particular attention to the growing influence of America in the development of Western culture. This has resonance 
with the 'outlier' position of the USA in a number of the Spirit Level analyses, not to mention the distinctive position occupied by the Scandinavian countries. Despite Dumazedier's optimism that, with enough effort and skill, comparative research might be undertaken despite the disparities in the available data, it is only recently that this has become a realistic possibility, as a result of the increasing availability of national time-use surveys and of crossnational surveys being conducted with leisure participation content, particularly in Europe. This section reviews the limited amount of existing cross-national income inequality-related leisure research based on such sources.

One of the pioneering international empirical studies of relevance to leisure was the Multinational Comparative Time-Budget Research Project, the results of which were published in Szalai (1971). Time-use surveys, typically based on survey instruments which include a 24 or 48 hour diary, lend themselves to international research because they are factual and constrained by the universal limitation of the 24-hour day. Coordination exercises such as the Harmonised European Time Use Survey (nd) and the Centre for Time Use Research at the University of Oxford (Fisher \& Robinson, 2010) draw together the results of such surveys from a number of countries, aligning idiosyncrasies in such matters as activity codes and age-ranges. However, it has not been possible to locate any published cross-national inequality-related leisure-specific research which makes use of these resources.

The Bowles and Park (2012) paper discussed above, deals with working hours rather than leisure time per se. This cannot be reliably extended directly to leisure time for three reasons. First, variations in work time may be at the expense of allocations to unpaid time other than leisure. Second, even if changes in leisure time are involved, this may be compensated for by corresponding earnings changes facilitating variable access to compensating forms of leisure activity/consumption. Third, differences in overall average working hours between countries can be affected by such factors as the level of participation of women and students in the workforce and the amount of part-time working. However, there is a case for empirical exploration of the theoretical link between leisure time, consumption and the Veblen effect, as discussed above, suggesting that leisure time as measured in time-use surveys might be explored as either a dependent or intervening variable.

A number of leisure-related activities have been identified by critics as behaving contrary to the Spirit Level thesis, including alcohol consumption, tobacco smoking and volunteering. Both Saunders (2010: 105) and Snowdon (2010a: 23) note that more unequal societies consume less alcohol. However, in response, Wilkinson and Pickett (2010b: 279) claim that if they were to deal with this variable it would be in the form of alcohol abuse rather than overall consumption (but they do not present data on this). Snowdon (2010a: 24) shows a very weak negative relationship between tobacco smoking and income inequality. It might be noted that levels of consumption in these commodities are particularly affected by government interventions, in taxation, regulation and direct campaigns, so any examination would present considerable challenges. Saunders (2010: 46) and Snowdon (2010a: 56-57) both find no relationship between volunteering activity and income inequality. However, using more recent and detailed data, significant negative relationships have been demonstrated, along with a significant positive relationship with GDP per head and varying patterns between volunteering for different types of organisation (Nichols \& Veal, 2013).

Reference has already been made to Spirit Level-style analysis of sport participation in 14 EU countries by Gratton et al. (2011), using 2004 Eurobarometer data. A more recent Eurobarometer survey has been conducted covering more countries, enabling this analysis to be further tested, as demonstrated below.

Lancee and Van der Werfhorst (2011) use data for 25 EU member countries from the 2006 EU Statistics on Income and Living Conditions (SILC) survey to explore relationships 
between income inequality and three composite measures of community participation: social, civic and cultural. Bivariate Spirit Level-type visual analysis shows a significant negative relationship between income inequality and each of the three measures. However, the main focus of the research is on multi-level (individual and country), multivariate models of participation related to: three alternative measures of income inequality; government social expenditure; GDP per head; and a number of socio-demographic variables. Cultural activity shows the weakest relationship with income inequality and a strong positive relationship with absolute household income. However, it is found that participation is less affected by household income in more equal countries and that public expenditure may have some impact. Cultural activity is omitted from the version of the study published in journal article form (Lancee \& Van der Werfhorst, 2012).

Szlendak and Karwackie (2012) use the 2007 Eurobarometer (278/67.1), also used in the current study, to explore cultural participation and income inequality across $22 \mathrm{EU}$ countries, but focus on just three activities: book reading, museum/gallery visiting and theatre-going. They find significant negative relationships: more unequal countries have lower levels of cultural activity. While they explicitly align cultural activity with the Spirit Level thesis, they ignore the various controversies and alternative analyses and explanations discussed above.

Some leisure researchers have begun to discuss the implications of The Spirit Level for leisure studies and leisure policies more broadly. For example, Nichols (2009) argues that more unequal societies, associated with consumption and status-driven increases in hours of work and reduced time for leisure and volunteering, raise questions of work-life balance and quality of life. Coalter (2013) examines policies for the promotion of sport participation in Britain in the light of the Spirit Level thesis. He notes that variation in the level of sports participation in Britain is class-related, a feature ignored by British policymakers in recent years in favour of the inclusion/exclusion perspective, as noted above. He accepts the Wilkinson and Pickett social status-related explanation, however, unlike Goldthorpe (2010), he is content to apply this income-related stratification proposition to a class-related analysis and concludes that, if the underlying cause of social problems is structural inequality in society, policies focussed on directly tackling the social problem of inequality in sport participation are unlikely to succeed.

With a few exceptions, the above empirical studies indicate a significant relationship between income inequality and leisure activity, although they are not without limitations. These limitations and other issues raised, together with the conclusions from the previous section, provide the basis for elaboration of the research questions to be addressed here.

\section{Research questions}

The substantive research questions addressed in this study are:

1. To what extent is leisure time and leisure participation related to income inequality when examined cross-nationally and using alternative measures of income inequality? This applies the Spirit Level-style analysis to leisure and follows up the methodological issue raised by a number of critics/studies.

2. If leisure time and leisure participation are found to be related to income inequality, how is this reflected in within-country relationships? This tests the Wilkinson and Pickett prescription on social gradients.

3. To what extent are other variables related to leisure time and leisure participation, specifically absolute income levels and national values? This extends the Spirit Level analysis as suggested by a number of critics/studies.

In addressing these questions a methodological issue is also considered, namely the choice of countries and alternative measures of income inequality. 
A number of issues discussed in the review are not considered in this paper, due to the limitations of resources, the single-paper format and availability of data. These are: smoking and alcohol consumption as leisure activities; direct analysis of the operation of social statusrelated propositions based on social-psychological frameworks; exploration of resourcerelated/ neo-materialistic ideas based on public expenditure levels; and the role of education.

\section{Methods/data/measurement}

The selection of countries, measurement of leisure and independent variables and analysis procedures are summarised below.

\section{Selection of countries}

As the study is based on secondary analysis of pre-existing and publicly available data, the selection of countries and of independent variables for the study is subject to the limitations of the data sets available, which are indicated in Table 1.

Table 1. Data sources

\begin{tabular}{|c|c|c|c|}
\hline Data item & Specifications & Sources & Countries included \\
\hline Leisure time & $\begin{array}{l}\text { Time not spent in paid or unpaid domestic } \\
\text { work, study or personal maintenance. }\end{array}$ & $\begin{array}{l}\text { Harmonised European } \\
\text { Time-use Survey, Fisher } \\
\text { \& Robinson (2010), } \\
\text { national web-sites }\end{array}$ & $\begin{array}{l}24 \text { countries which have } \\
\text { undertaken time-use } \\
\text { surveys }\end{array}$ \\
\hline $\begin{array}{l}\text { Cultural } \\
\text { activity }\end{array}$ & $\begin{array}{l}\text { Participation at least once in year prior to } \\
\text { interview in: attendance at: cinema; ballet/ } \\
\text { dance performance; theatre; sport event; } \\
\text { concert; public library; historic site; } \\
\text { museum/gallery; reading books. Index (0- } \\
\text { 100): sum of above divided by } 9 \text {. }\end{array}$ & $\begin{array}{l}\text { Eurobarometer } 278 \\
(67.1) \text { 2007, } \\
\mathrm{N}=27,700 \text {, European } \\
\text { Commission (2007) }\end{array}$ & $\begin{array}{l}27 \text { EU members, less } \\
\text { Bulgaria \& Romania } \\
\text { (income }<\$ 20 \mathrm{~K} \text { ), } \\
\text { Luxembourg \& Malta } \\
\text { (popn }<1 \text { million) }\end{array}$ \\
\hline $\begin{array}{l}\text { Sporting \& } \\
\text { recreational } \\
\text { activity }\end{array}$ & $\begin{array}{l}\text { Participation in: a. sport and b. physical } \\
\text { recreation activities (e.g. cycling, walking, } \\
\text { dancing, gardening) at least once in week } \\
\text { prior to interview. }\end{array}$ & $\begin{array}{l}\text { Eurobarometer } 334 \\
(72.3), 2009 \text {, } \\
\mathrm{N}=26800 \text { European } \\
\text { Commission (2009) }\end{array}$ & As above \\
\hline $\begin{array}{l}\text { Income } \\
\text { inequality }\end{array}$ & $\begin{array}{l}\text { Gini coefficient, 2000-2010 ( } 0=\text { complete } \\
\text { equality, } 100=\text { complete inequality) }\end{array}$ & Gini Project (nd) & $\begin{array}{l}\text { Available for all the above } \\
\text { countries }\end{array}$ \\
\hline GDP/Head & GDP/Head, \$'000s & $\begin{array}{l}\text { Groningen University } \\
\text { Conference Board } \\
\text { (Annual) }\end{array}$ & $\begin{array}{l}\text { Available for all the above } \\
\text { countries }\end{array}$ \\
\hline
\end{tabular}

In regard to time use, only 24 countries were identified which have conducted time-use surveys with results available in databases or in suitable on-line format. It can be seen that five east-European , former communist, countries fall below the income cut-off point. The analysis was conducted with and without these countries included.

In regard to the sport and cultural participation analysis, the European Commission's Eurobarometer surveys provide unique cross-national data sets based on surveys conducted across all 27 member states. Wilkinson and Pickett (2010a: 280) use a GDP per capita cut-off level of $\$ 20 \mathrm{k}$, but in the interest of maximising the sample size, in this study the cut-off was $\$ 15 \mathrm{k}$, thus excluding just Bulgaria and Romania. However, analyses were also conducted excluding the four \$15-19k countries (Hungary, Poland, Lithuania, Latvia). In The Spirit Level a population cut-off of three million was imposed, but in this exercise a cut-off of one million, was used, resulting in the exclusion of Luxembourg (pop. 0.5 million) and Malta ( 0.45 million). This resulted in a sample of 23 European countries.

\section{Activities}

Leisure time is defined as time not spent in paid work, domestic work/childcare or personal 
care, and information is drawn from published national time-use surveys, typically based on self-completed diaries. In this exercise it is measured in hours per week for persons aged 1864 years (except for the USA which includes persons 15 and over).

The selection of individual leisure activities is determined by the design of the two most recent Eurobarometer surveys to include leisure activities. As shown in Table 1, the 2009 Eurobarometer 334 covered participation in sport and non-sport physical recreation activities. The 2007 Eurobarometer 278 covered nine cultural activities and, in addition, a composite index of the average of the nine percentage participation rates was compiled. The measure for each activity for each country is the percentage of the population, aged 15 and over, participating in the activity at least once in the previous year for cultural activities, and in the week before interview for sport activity. Information is also available on frequency of participation (1-2 time, 3-5 times and more than 5 times) but this is not drawn on for this study.

Income inequality and income

An OECD (2011: 26) report notes the variety of ways in which income inequality might be measured. The most common measures refer to all households and all income, net of income tax and benefits and adjusted for size of household. Such a measure can then take a number of forms:

- a percentile ratio of aggregate income shares - for example, in The Spirit Level the measure used is the ratio of the share of total income received by the top 20 percent to that received by the bottom 20 per cent (S80/S20);

- a percentile ratio related to the level of income - for example, the measure used by Bowles and Park (2005) was the ratio of the cut-off annual income for the top 10 per cent to the median income (P90/P50);

- the Gini coefficient, or index, which takes a value between 0 for complete equality (all persons or households have the same income) and 1, or 100, for maximum inequality (one person or household has all the income) - as Wilkinson and Pickett (2010a: 18) state, this is the more widely accepted measure of inequality;

- the 'Robin Hood' ratio - the proportion of total income which would have to be redistributed to achieve complete equality; or

- the mean distance of individual incomes to the median income (MDMI), which has some similarities with a standard deviation and can be divided into two measures relating to those above the median and those below - this measure was used by Lancee and Van de Werfhorst (2011), discussed above.

The last two of these are not widely used and data are not readily available from organisations such as the OECD and Eurostat. Of the first three: S80/S20 was used in The Spirit Level. Both S80/S20 and P90/P50 reflect inequalities arising from the high end of the income spectrum, which is plausibly linked to the upward emulation process of the Veblen effect and related theory, while the Gini index is the most widely used and readily available measure. These three measures were therefore evaluated for use in this exercise.

For absolute income, Gross Domestic Product (GDP) per head of population is used in this study.

\section{National culture/tradition}

While national culture and traditions could be explored in a number of ways, in this exercise they are addressed by including a variable on the percentage of Protestants among those who profess to adhere to a religious denomination, which is readily available from the European 
and World Values Surveys. This is not to suggest that all survey respondents identifying as Protestants are guided by corresponding religious values, but that the variable is a plausible indicator of aspects of the historically-based cultural values of the country. The particular measure, being a percentage, has the advantage of maintaining the simplicity of a scale variable.

\section{Analysis procedures and presentation}

The initial analysis uses bivariate correlation to maintain comparability with the Spirit Level presentation. Some multiple regression involving GDP/head and Protestantism is also included. Regression coefficients significant at the 0.01 level are marked ${ }^{* *}$, those at the 0.05 level are marked * and those at the 0.10 level are marked +. Additional analyses are conducted excluding outliers and countries with GDP/head of less than US\$20k and the results noted in the text or at the base of Figures/Tables.

\section{Results}

We consider first leisure time, with a worldwide sample, then leisure activities (cultural and sporting), based on European data. The commentary in this section is quite technical and descriptive in guiding the reader through a number of tables and diagrams but, arguably, the latter are relatively self-explanatory.

\section{Leisure time}

It is noted above, that for measures of well-being to be considered in The Spirit Level framework, they should display a within-country social gradient, with poorer people being at a disadvantage compared with the rich. Figure 2 shows that, in the case of leisure time, a number of countries exhibit a gradient but in the opposite direction from that stipulated: the rich have less leisure time than the poor. However, while leisure studies scholars may view increased leisure time as an indicator of increased well-being, it could be argued that, if it is caused by lowly paid workers having low working hours, this might be seen as a negative. Figure 3 shows another group of countries where the gradient goes in the opposite direction or is flat. The countries do have their distinctive features - three are former eastern bloc members, Spain has the highest unemployment rate in Western Europe and Sweden is probably the most equal of all the EU member states - but whether these feature explain the patterns is not known. Given that the gradient stipulation is observed rather than argued theoretically in The Spirit Level, this rather mixed picture is not seen as a barrier to continuing to examine the relationship between income inequality and leisure time at the cross-national level.

Table 2 shows correlations between leisure time and three measures of income inequality (Gini index, S80/S20 and P90/P50), GDP/head and the level of Protestantism for all 24 countries for which time use survey date are available and for four sub-sets of countries with various exclusions. It can be seen that the highest correlation coefficients are with the P90/P50 measure, making it possibly the preferred income inequality measure for this exercise, particularly in view of its link with the Veblen effect. The relationship between leisure time and GDP/head is significant but weaker than for income inequality, while the relationship with the Protestantism variable is generally weak. 
Figure 2. Leisure time by income quartile, selected countries: downward gradient

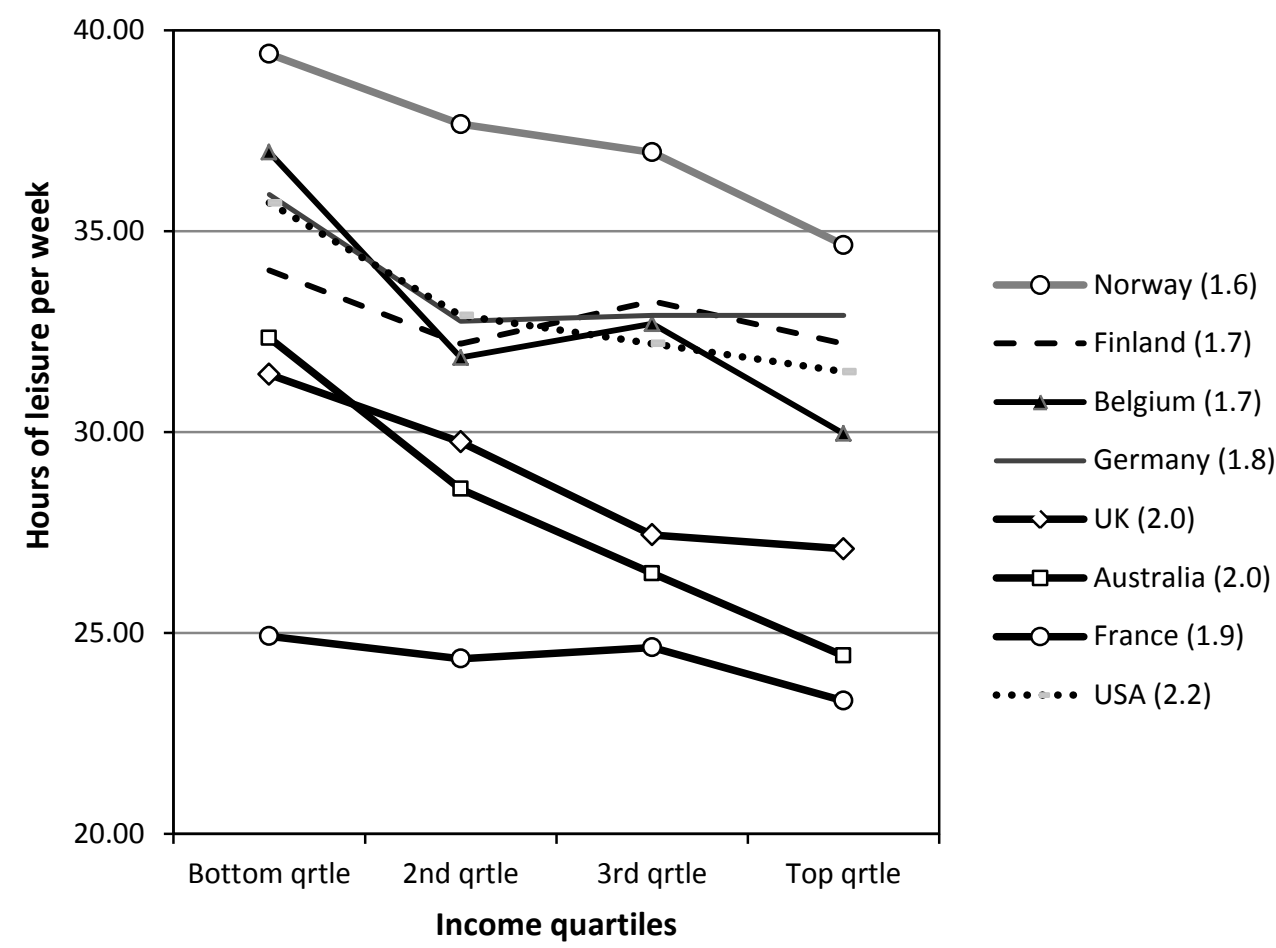

Data source: European: HETUS 18-64 year-olds (www.h2.scb.se/tus/tus/) . Others: individual country time use survey web-sites. Refers to persons with own incomes. Figures in brackets are P90/P50 ratios.

Figure 3. Leisure time by income quartile, selected countries: flat \& upward gradient

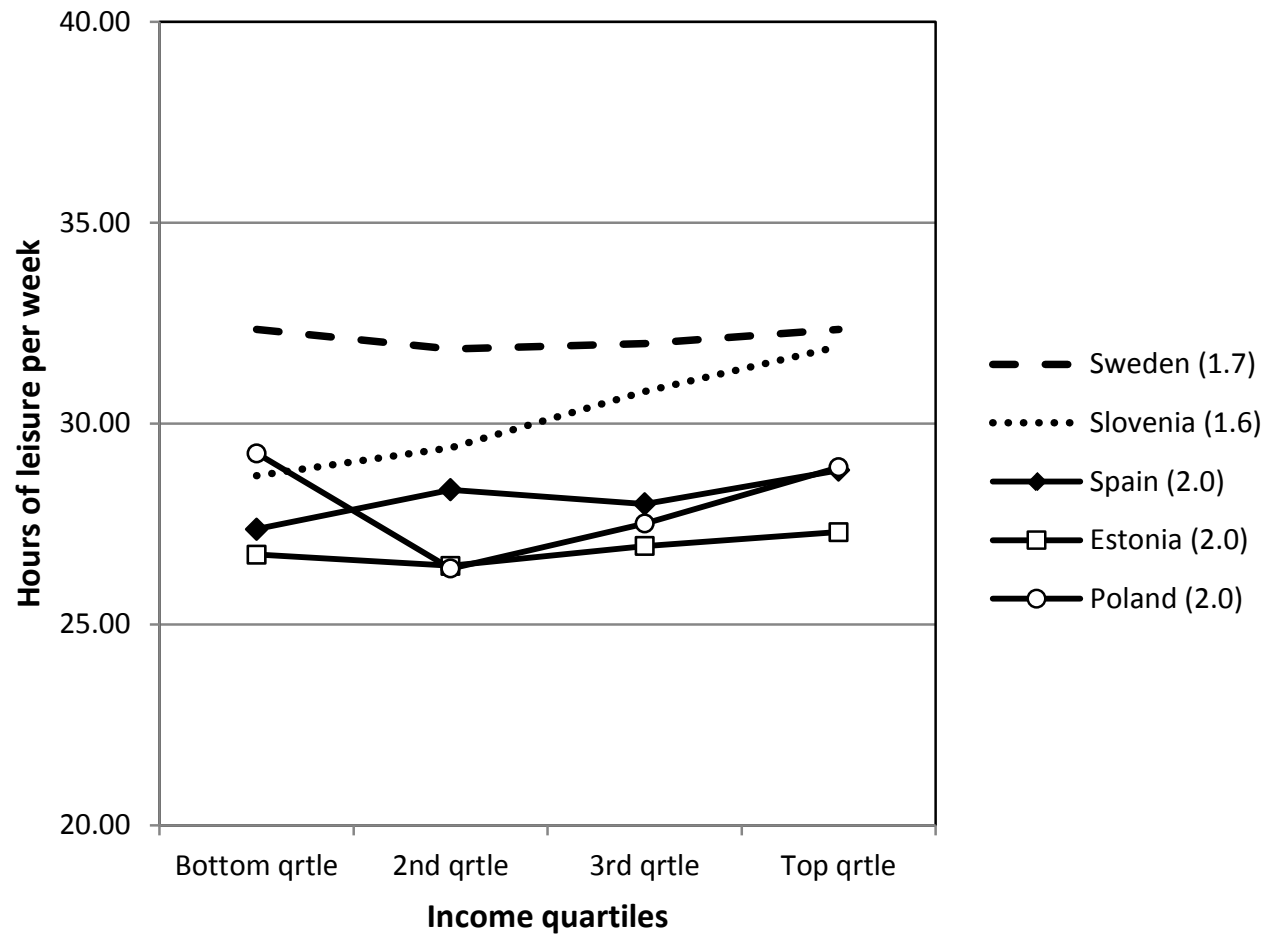

Data sources etc.: see Figure 2 
Table 2. Correlations (r) between mean leisure time and income inequality measures, GDP/head and Protestantism, selected countries

\begin{tabular}{lccccc}
\hline Country set (N) & \multicolumn{3}{c}{ Income inequality } & GDP/head & \multicolumn{2}{c}{ Protestant } \\
\cline { 2 - 4 } & $\mathbf{S 8 0 / S 2 0}$ & Gini index & P90/P50 & US\$'000s & \% \\
\hline All with time-use surveys (24) & $-0.61^{* *}$ & $-0.50^{*}$ & na & $0.57 * *$ & 0.27 \\
Excl. Latvia/Lithuania (22) & $-0.55^{* *}$ & $-0.46^{*}$ & $-0.68^{* *}$ & $0.48^{*}$ & 0.27 \\
GDP/head > \$15K (21) & $-0.56^{* *}$ & $-0.43^{*}$ & $-0.69^{* *}$ & $0.45^{*}$ & 0.27 \\
GDP/head > \$20K (19) & $-0.58^{* *}$ & $-0.43^{*}$ & $-0.68^{* *}$ & $0.52^{*}$ & 0.21 \\
Excl. outlier: Portugal (23) & $-0.62^{* *}$ & $-0.45^{*}$ & $-0.57^{* *}$ & $0.57^{* *}$ & 0.26 \\
\hline
\end{tabular}

Data sources: time-use surveys, see Table 1 . na $=$ measure not available for all countries

The effects of the analyses conducted on reduced data sets are mixed. Excluding Latvia and Lithuania reduces the correlation coefficients, but they remain statistically significant. Omitting countries with GDP/head of less than \$20K should improve the fit of the models according to the Spirit Level income criterion but this is not the case. Excluding the outlier, Portugal, should result in a poorer fit, but in two of the four cases there is virtually no effect. In general, therefore, it can be said that the results are quite robust in terms of country selection.

To provide comparison with the Spirit Level diagrams, a visual presentation of the relationship between leisure time and the P90/P50 is presented in Figure $4 .{ }^{\text {iv }}$ In view of the strength of the relationship with GDP/head and the possibility that it might be an additional influence, this is also depicted, in Figure 5.

Figure 4. Leisure time by income inequality (P90/P50), 22 countries

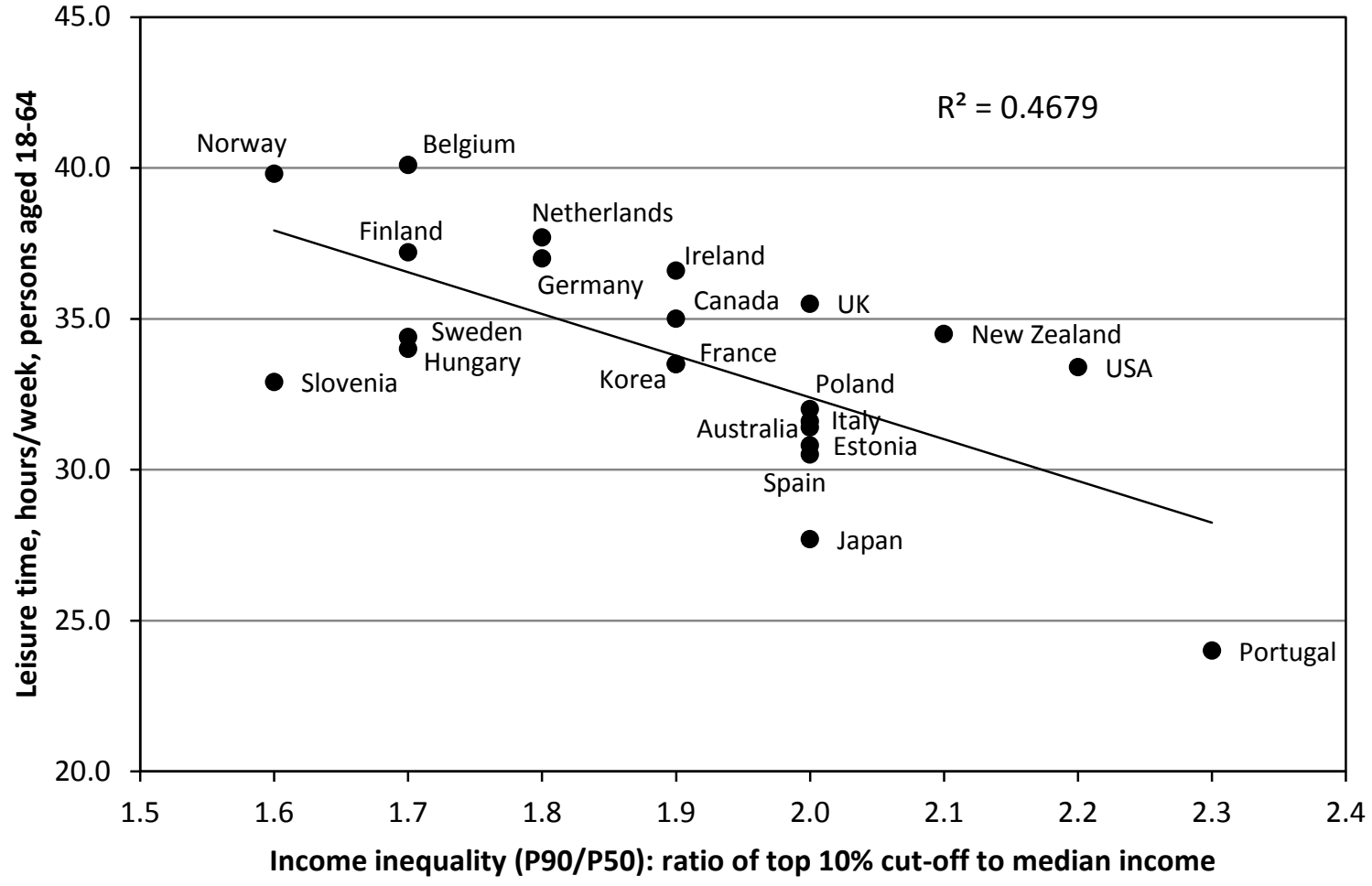

Data sources: see Table 2. 
Figure 5. Leisure time by GDP/head, 24 countries

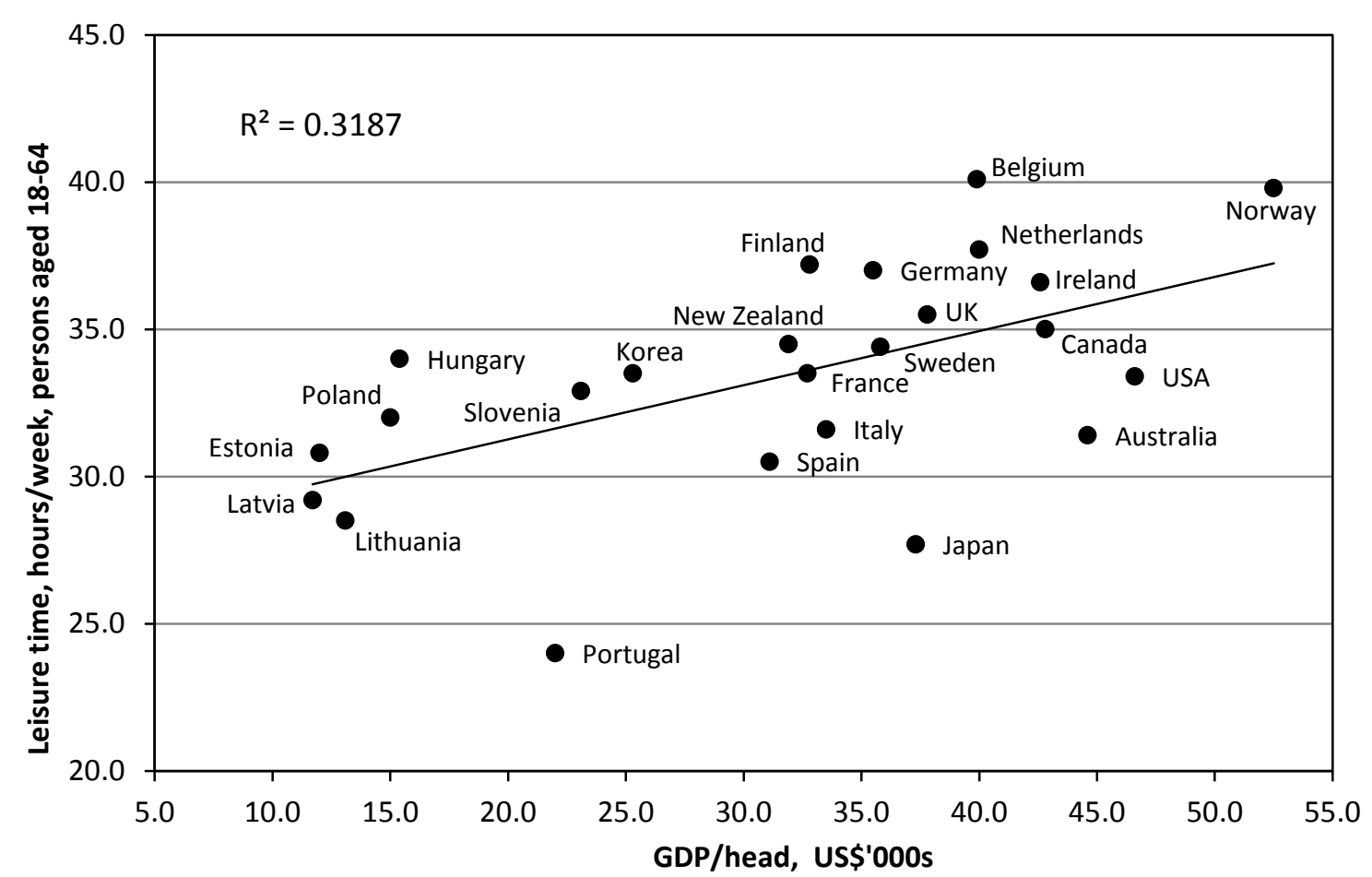

Data source: See Table 2. Omit low income countries (GDP/head $<\$ 20 \mathrm{~K}): r=0.52 *$. Omit outliers, Japan and Portugal: $r=0.66^{* *}$.

Proceeding with the P90/P50 measure of income inequality, Table 3 presents multiple regression analysis for the 22-nation data set for which data are available. The two models, with and without Protestantism, are both significant at the 0.01 level, but the addition of the Protestantism variable does not add significantly to the explanatory level of the model.

Table 3. Multiple regression: leisure time and income inequality (P90/P50), income and Protestantism, selected countries

\begin{tabular}{|c|c|c|c|c|c|c|}
\hline & \multirow[t]{2}{*}{$\mathbf{R}$} & \multirow[t]{2}{*}{$\mathbf{R}^{2}$} & \multirow[t]{2}{*}{ Adjusted $\mathbf{R}^{2}$} & \multicolumn{3}{|c|}{ Independent variables } \\
\hline & & & & P90/P50 & GDP/head & \% Protestant \\
\hline & & & & \multicolumn{3}{|c|}{ Standardised coefficients } \\
\hline Model 1 & $0.79 * *$ & 0.63 & 0.60 & $-0.64 * *$ & $0.40^{*}$ & na \\
\hline Model 2 & $0.89 * *$ & 0.64 & 0.57 & $-0.65 * *$ & $0.36 *$ & 0.09 \\
\hline
\end{tabular}

Data source: see Table 1. Excluding Portugal: Model 1: $\mathrm{R}=0.69 * *$, Model 2: $\mathrm{R}=0.69 *$. GDP/head $>$ \$20k: Model 1: $\mathrm{R}=0.81^{* *}$, Model 2: $\mathrm{R}=0.81^{* *}$

For the Spirit Level thesis to be confirmed in full it is necessary for the leisure time in more equal countries to be higher across all income groups. This is broadly confirmed in Figures 2 and 3 above.

Conclusions regarding leisure time

In general, therefore, these findings support the Spirit Level thesis applied to leisure time: there is a significant negative relationship between income inequality and leisure time crossnationally: more unequal countries have less leisure time. However, the analysis also shows that, for this purpose, the P90/P50 measure of income inequality is superior to the S80/S20 used in The Spirit Level and to the Gini index used by others, lending support to the idea of the Veblen effect. GDP/head is also found to be a significant variable. Protestantism is less 
significant, suggesting that national values may not be important in this context or that the Protestant measure does not adequately reflect them.

\section{Leisure activities}

Turning to specific leisure activities, we again examine the question of within-country gradients. As noted above, the Eurobarometer surveys do not include income but do include occupation, which is highly correlated with income. Figures 6 and 7 show indicative data for Sweden and Finland (high income equality) and Britain and Portugal (high income inequality), for museum/ gallery attendance (which correlates strongly with the composite cultural index at country level) and for sport. Except for sport in Sweden, these show clear gradients.

Figure 6. Museum/gallery visiting by occupation, selected countries, 2007

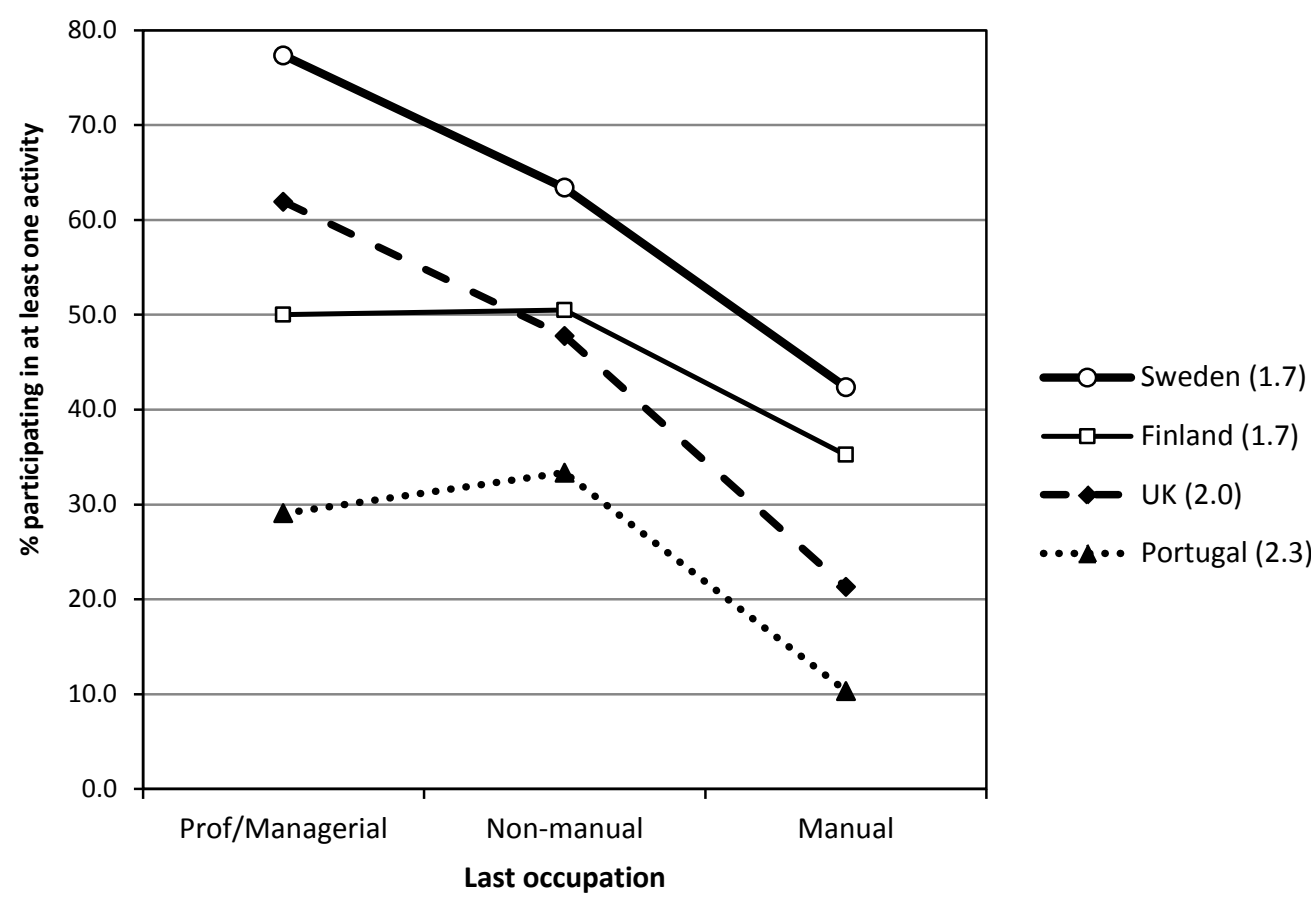

Data source: see Table 2. In brackets: P90/P50 score 
Figure 7. Sport participation by occupation, selected countries, 2009

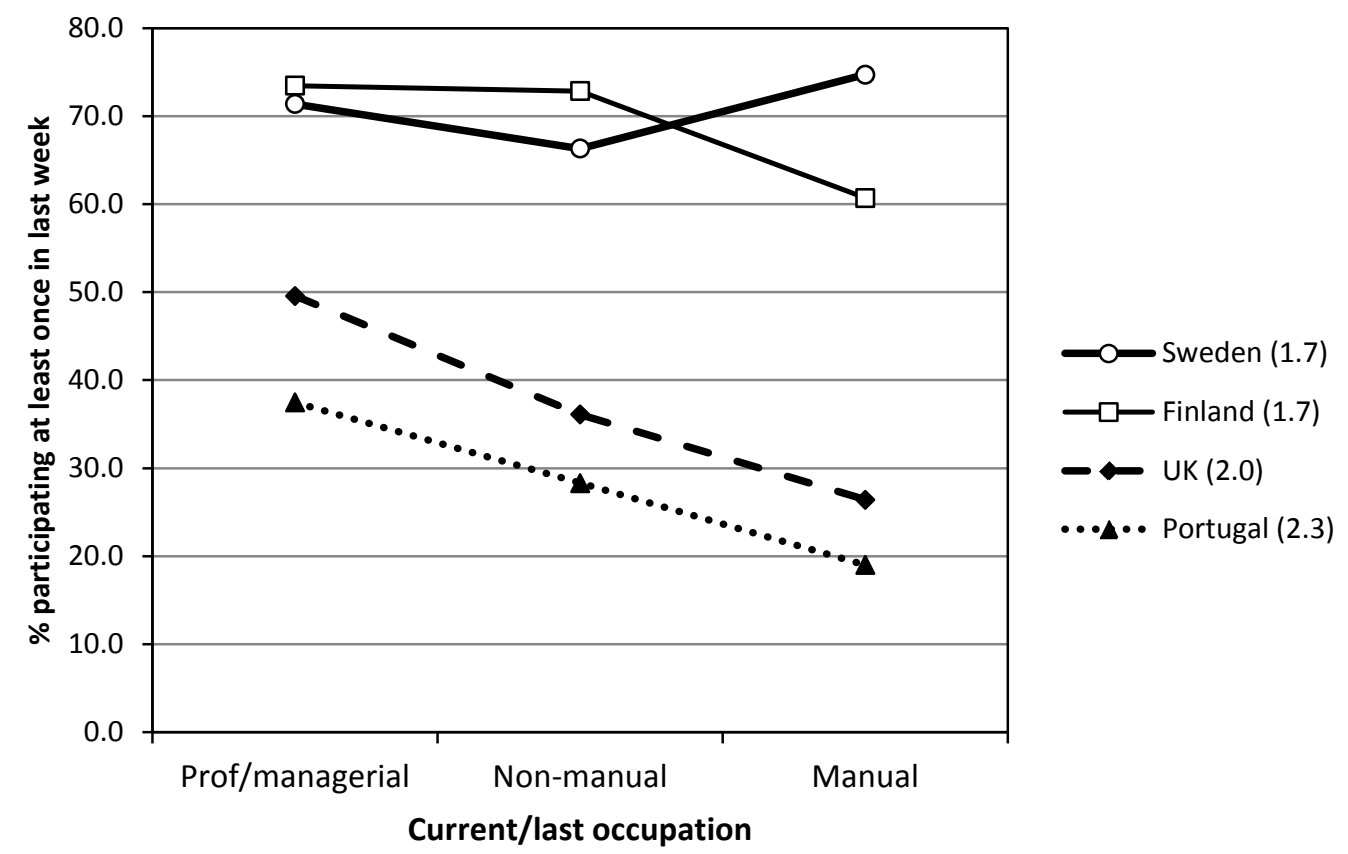

Data

source: See Table 2. In brackets: P90/P50 score

Table 4 presents correlation coefficients for the three measures of income inequality, GDP/head and the proportion of Protestants related to participation in: nine cultural activities; the composite cultural participation index; and sport/physical recreation activities. As with leisure time, the highest income inequality correlations are with the P90/P50 measure, again providing support for the Veblen effect and for use of P90/P50. The Protestantism variable shows strong relationships with all activities except the more commercial cinema and sporting event attendance. GDP/head has the lowest coefficients overall, but with high values for cinema and sport. Figures 8-11 provide visual representations of the relationships for P90/P50 and GDP/head for the cultural index and sport.

Table 4. Correlation between measures of income inequality, GDP/head and cultural and sport participation, 23 European countries

\begin{tabular}{llllll}
\hline Activity & S80/S20 & Gini index & P90/P50† & GDP/head & \% Protestant \\
\hline Cultural activities & & & & & $0.87^{* *}$ \\
Cinema & $-0.54^{* *}$ & $-0.51^{*}$ & -0.43 & -0.47 \\
Ballet, dance, opera & -0.31 & -0.38 & $-0.48^{*}$ & 0.36 & $0.71^{* *}$ \\
Theatre & -0.33 & -0.39 & -0.41 & $0.40^{*}$ & $0.59^{* *}$ \\
Sport event & $-0.50^{*}$ & $-0.54^{* *}$ & $-0.44^{*}$ & $0.48^{*}$ & 0.29 \\
Concert & -0.23 & -0.24 & $-0.54^{*}$ & 0.16 & $0.53^{* *}$ \\
Public library & $-0.45^{*}$ & $-0.43^{*}$ & $-0.51^{*}$ & 0.34 & $0.78^{* *}$ \\
Historic monuments etc. & $-0.51^{*}$ & $-0.51^{*}$ & $-0.64^{* *}$ & 0.35 & $0.67^{* *}$ \\
Book reading & $-0.50^{*}$ & $-0.58^{* *}$ & $-0.57^{* *}$ & 0.37 & $0.64^{* *}$ \\
Museums/ galleries & $-0.43^{*}$ & $-0.48^{*}$ & $-0.53^{*}$ & $0.50^{*}$ & $0.78^{* *}$ \\
Index, cultural activity & $-0.52^{*}$ & $-0.54^{* *}$ & $-0.61^{* *}$ & $0.53^{*}$ & $0.73^{* *}$ \\
\hline Sport/physical recreation & & & & & 0.27 \\
Physical recreation & -0.32 & -0.39 & -0.43 & $0.61^{* *}$ \\
Sport & $-0.52^{*}$ & $-0.48^{*}$ & $-0.49^{*}$ & $0.65^{* *}$ & $0.65^{* *}$ \\
\hline
\end{tabular}

Data source: see Table 1 † Excludes Latvia, Lithuania 
Figure 8. Cultural participation by income inequality, EU countries, 2007

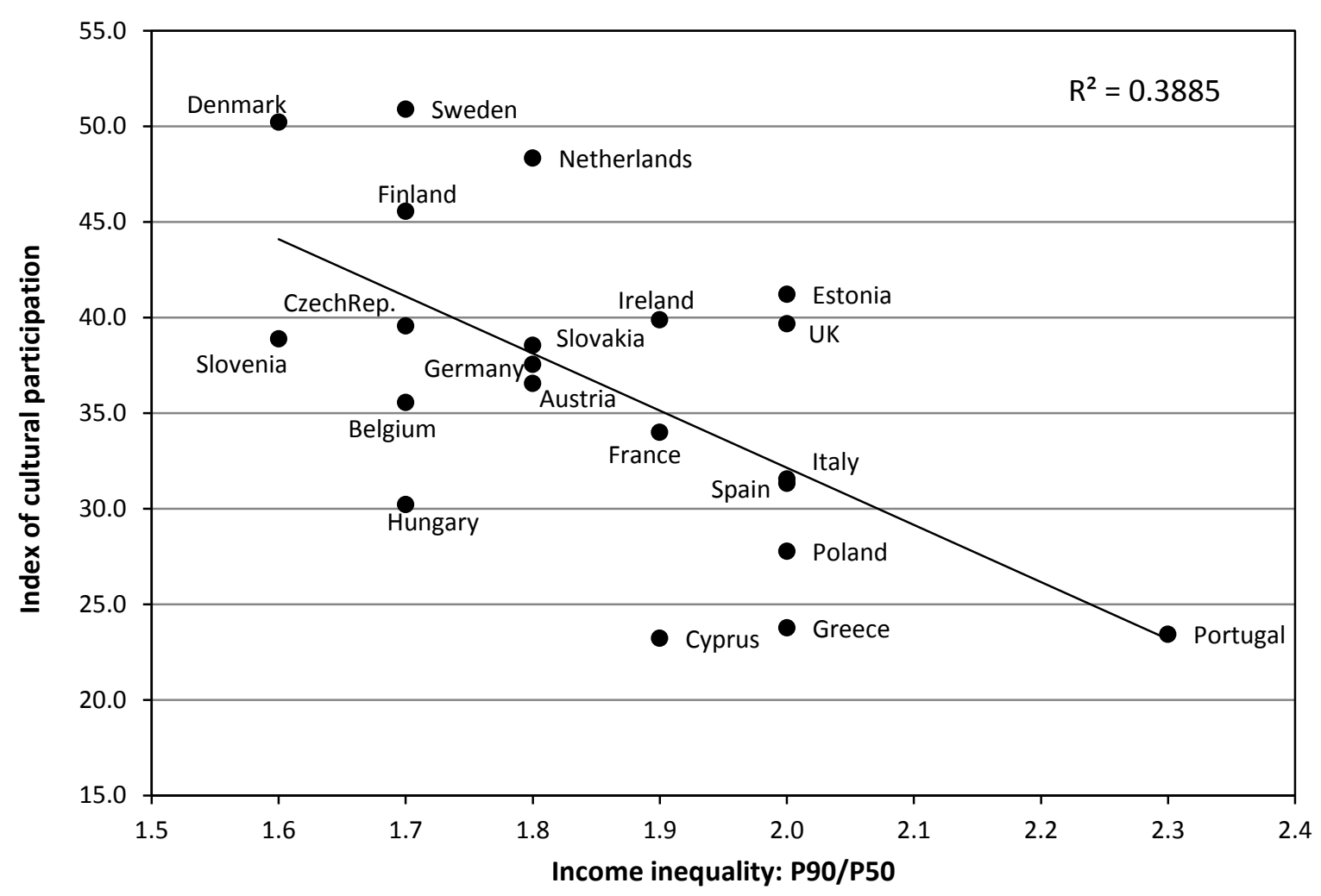

Data source: see Table 2. Omit outlier: Portugal: $r=-0.54$.

Figure 9. Cultural participation by GDP/head, EU countries, 2007

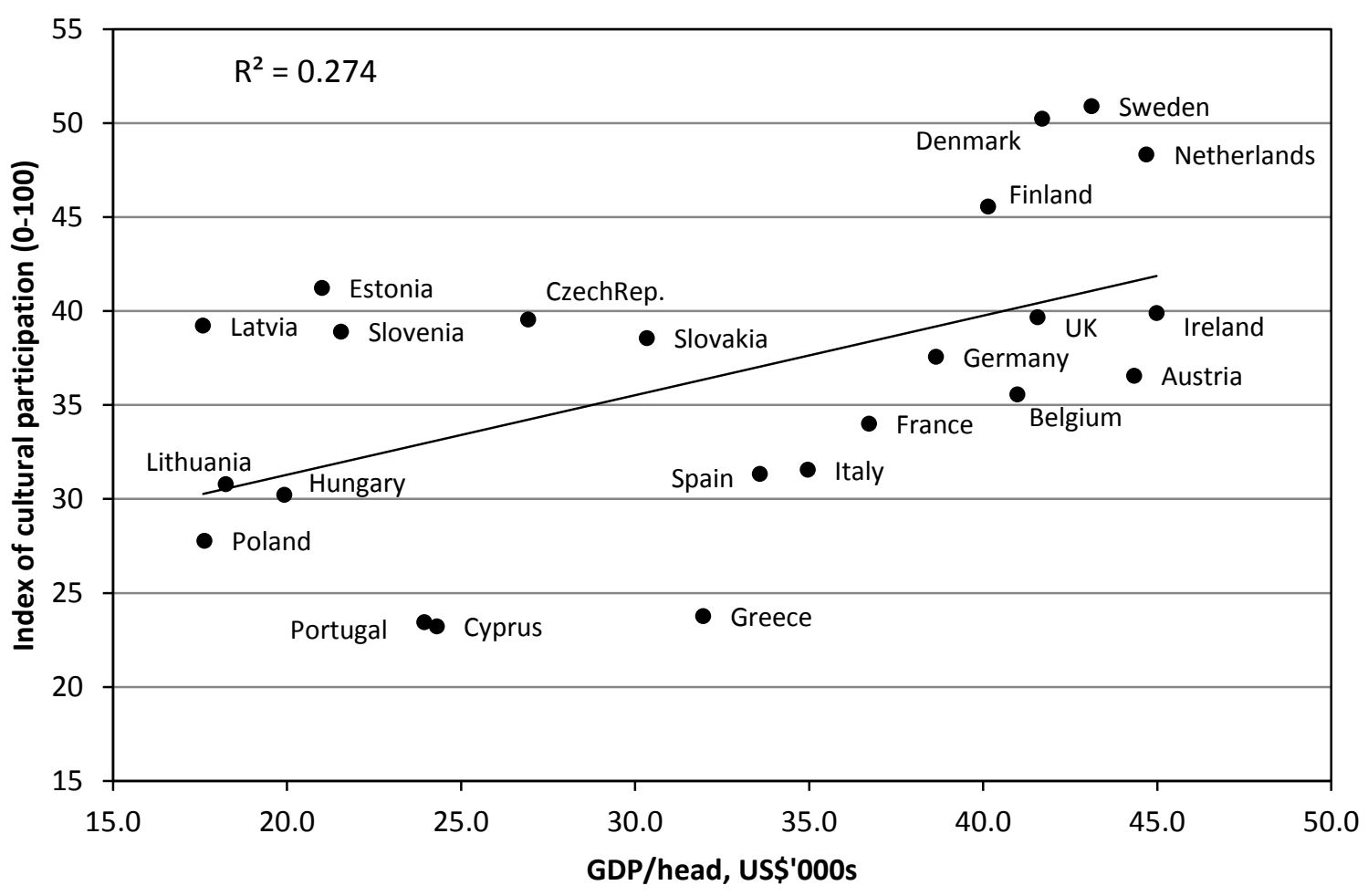

Data source; see Table 2. Outliers: None. Omit low income $(<\$ 20 \mathrm{k})$ countries: $\mathrm{r}=0.55^{*}$. 
Figure 10. Sport participation by income inequality, European countries, 2009

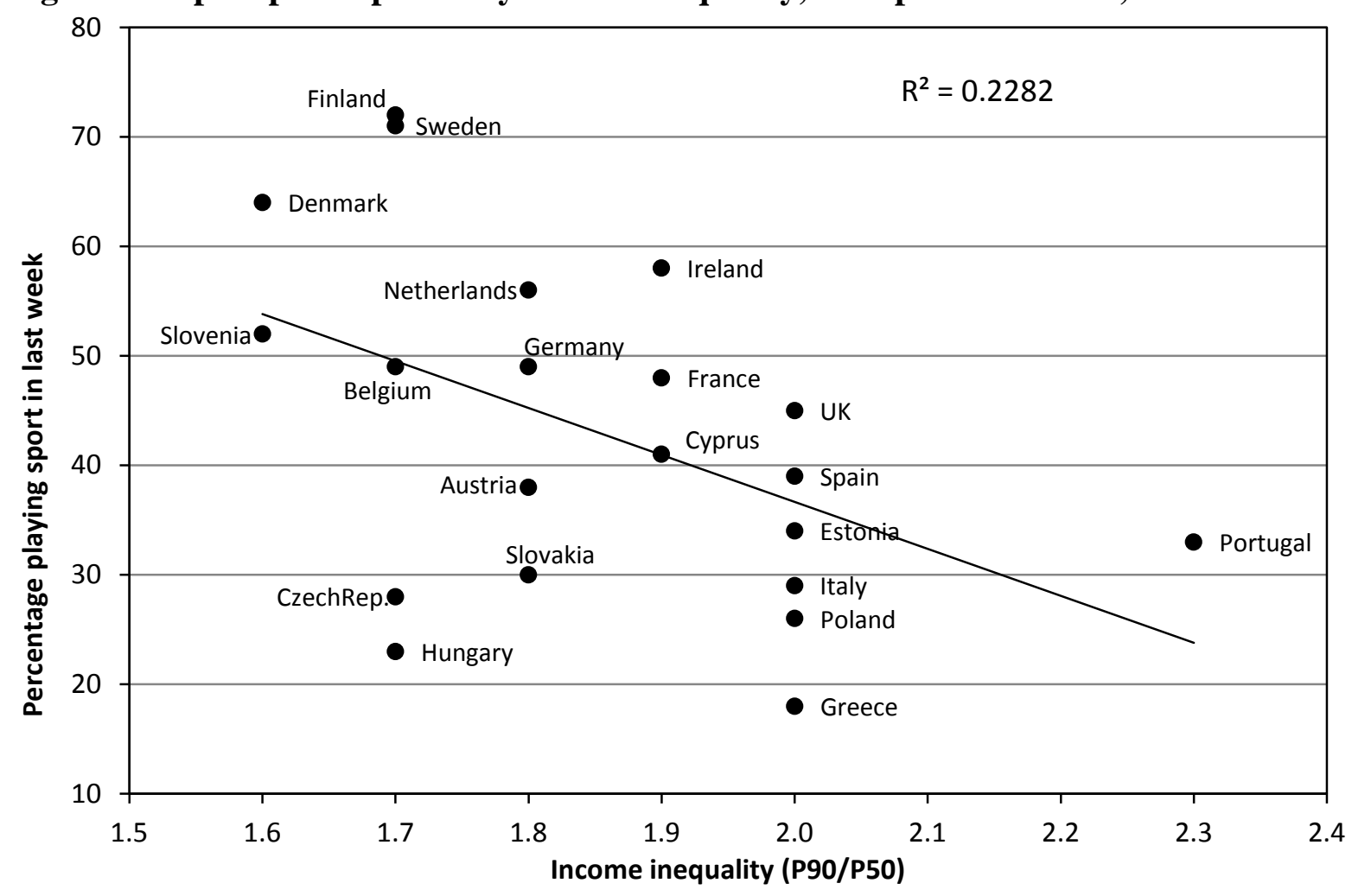

Data source: see Table 2. Exclude outlier: Portugal: $r=-0.45$

Figure 11. Sport participation by GDP/head, European countries, 2009

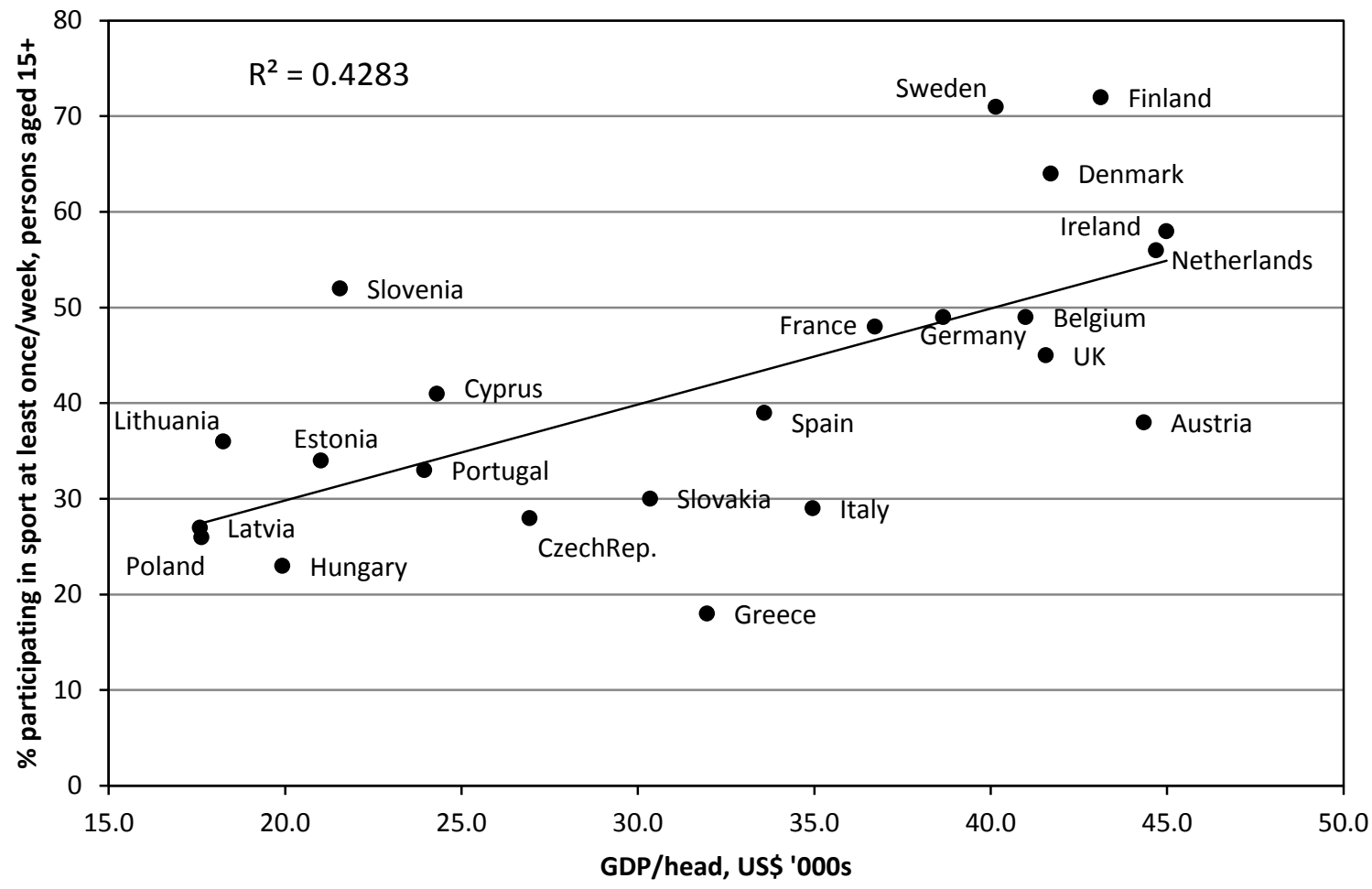

Data source: see Table 2. Outliers: none. Excluding low income (<US\$20k) countries: $\mathrm{r}=0.61^{* *}$ 
The analyses with reduced data sets, in this case just excluding countries with incomes below $\$ 20 \mathrm{~K}$, are not reproduced here. They produced similar results to those for leisure time, that is, some changes, but no loss of significance.

Table 5 presents the results of multiple regression analysis for income inequality (P90/P50), GDP/head and Protestantism. The model produces significant results for all activities, but in regard to overall model fit, the activities fall into four groups:

- Cinema and sporting event attendance: a negative, but not significant, relationship with Protestantism and a significant relationship with GDP/head. The model fits cinema attendance well, but is much weaker for sporting events.

- Museum/gallery visiting, overall cultural index and sport: all three independent variables play a part.

- Concerts, public libraries and historic buildings etc.: income inequality and Protestantism are significant, but GDP/head is not.

- Ballet etc., theatre and physical recreation: only Protestantism is significant.

Table 5. Cultural and sporting participation: multivariate analysis, 22 countries

\begin{tabular}{|c|c|c|c|c|c|c|}
\hline \multirow[t]{2}{*}{ Activity } & \multirow[t]{2}{*}{$\mathbf{R}$} & \multirow[t]{2}{*}{$\mathbf{R}^{2}$} & \multirow[t]{2}{*}{ Adjusted $\mathrm{R}^{2}$} & \multicolumn{3}{|c|}{ Independent variables: } \\
\hline & & & & P90/P50 & GDP/head & Protestantism \\
\hline & & & & \multicolumn{3}{|c|}{ Standardised coefficients (Beta) } \\
\hline Cinema & $0.88^{* *}$ & 0.77 & 0.73 & $-0.26+$ & $0.80^{* *}$ & -0.04 \\
\hline Ballet etc. & $0.79 * *$ & 0.63 & 0.56 & -0.24 & 0.20 & $0.57 * *$ \\
\hline Theatre & $0.65 *$ & 0.43 & 0.33 & -0.23 & 0.22 & $0.41+$ \\
\hline Sport events & $0.59+$ & 0.35 & 0.23 & -0.36 & $0.41+$ & -0.03 \\
\hline Concerts & $0.71 * *$ & 0.50 & 0.41 & $-0.38+$ & 0.13 & $0.41+$ \\
\hline Public library & $0.82 * *$ & 0.68 & 0.62 & $-0.28+$ & -0.01 & $0.69 * *$ \\
\hline Historic buildings etc. & $0.80 * *$ & 0.65 & 0.58 & $-0.46 * *$ & 0.12 & $0.46^{*}$ \\
\hline Read books & $0.74 * *$ & 0.55 & 0.47 & $-0.40^{*}$ & 0.11 & $0.45 *$ \\
\hline Museums/galleries & $0.86^{* *}$ & 0.73 & 0.69 & $-0.29 *$ & $0.25+$ & $0.58 * *$ \\
\hline Culture index & $0.86^{* *}$ & 0.74 & 0.70 & $-0.39 * *$ & $0.29 *$ & $0.47 * *$ \\
\hline Physical recreation & $0.66^{*}$ & 0.44 & 0.34 & -0.25 & 0.10 & $0.49 *$ \\
\hline Sport & $0.82 * *$ & 0.67 & 0.61 & $-0.27+$ & $0.41 *$ & $0.41 *$ \\
\hline
\end{tabular}

Data source: see Table 1

It is difficult to explain these differences, except for cinema and sporting events, for which the significance of GDP/head is likely to be related to their more commercial nature. However, it can be concluded that all cultural activities are not the same in regard to relationships to the variables involved. It is notable that the model fits the two aggregate participation indicators - cultural index and sport - well. However, there are differences among individual cultural activities suggesting that there may be similar variability among individual sports. Such variability reflects Frank's (2005) contention that goods and services vary in the extent to which they are 'positional'.

For the Spirit Level thesis to be confirmed in full it is necessary for the level of participation in more equal countries to be higher across all income groups. This is broadly confirmed in Figures 4 and 5 discussed above, which show clearly that the differences in inter-country participation rates apply to all occupation groups, with the one exception of UK museum-gallery visiting for the professional/ managerial group. 


\section{Summary regarding leisure activities}

These findings broadly confirm the findings of Gratton et al. (2011) in regard to sport, based on earlier survey data and also follow up their idea of different cultural traditions/values by use of the Protestant variable. The Szlendak and Karwacki (2012) findings are also confirmed in relation to the three activities they covered (theatre-going, book reading and museum/ gallery visiting), but with lower correlations in the bivariate analysis and stronger relationships in the multivariate analysis using P90/P50. Szlendak and Karwaki use the same participation data sources, but 2004 Eurostat Gini coefficients, but it has not been possible to reproduce their results. In regard to the findings of Lancee and Van de Werfhorst (2011), the variation among activities in the strength of the relationships may explain why their composite index of cultural participation failed to identify a strong relationship with income inequality.

\section{Conclusions}

In regard to the three research questions posed:

1. It can be concluded that there is a significant negative relationship between income inequality and amount of leisure time and levels of participation in cultural and sporting activities when examined cross-nationally: more equal countries have more leisure time and higher levels of cultural and sporting participation.

2. The research confirms the proposition that, in more equal countries, increased leisure time and higher levels of participation in cultural and sporting leisure activities are experienced across all income/socio-economic groups.

3. In addition to income inequality, it was found that participation levels are also related positively to the level of GDP per capita and to cultural traditions/value as indicated by the proportion of the religiously affiliated population that identify as Protestant. The patterns of relationships, however, vary among activities.

Methodologically, it was found that the most suitable measure of income inequality was the P90/P50 measure rather than the S80/S20 measure used in The Spirit Level. Theoretically, this may be said to reflect the existence of the Veblen effect: that is, the proposition that people's consumption patterns partly reflect not just their own income but the consumption patterns of higher income groups.

The implications of these findings for public policy directed at promoting increased leisure time and/or cultural and sporting participation are that policy-makers in countries with relatively unequal income distributions face an uphill task, as Coalter (2013) has suggested. It seems likely that success is more likely in more egalitarian environments. However, while increased cultural and sporting activity is likely to affect all income/socio-economic groups, in regard to leisure time, it may favour the more well-off. The political nature of the book which prompted this research, The Spirit Level, is clear to both its supporters and critics; the findings of this research suggest that, to be effective, policies to promote leisure time and cultural and sporting participation will need to be seen as part of a broader political project.

\section{References}

Australian Bureau of Statistics (ABS) (2011). Attendance at cultural venues/events: 2009-10. (Cat. No. 4114.0). Canberra: ABS, available at: www.abs.gov.au.

Bagwell, L.S., \& Bernheim, B.D. (1996). Veblen effects in a theory of conspicuous consumption. American Economic Review, 86(3), 349-73.

Belfiore, E. (2002). Art as a means of alleviating social exclusion: does it really work? A critique of instrumental cultural policies and social impact studies in the UK. International Journal of Cultural Policy, 8(1), 91-106. 
Bowles, S., \& Park, Y. (2005). Emulation, inequality, and work hours: was Thorstein Veblen right? Economic Journal, 115, F397-F412.

British Travel Association (BTA)/University Keele (1967). Pilot national recreation survey, report no. 1. London BTA.

Bourdieu, P. (1984). Distinction: a social critique of the judgement of taste. London: Routledge and Kegan Paul.

Centre for Leisure \& Sport Research (2002). Count me in: the dimensions of social inclusion through culture and sport. Report to the Department for Culture, Media \& Sport, Leeds: Centre for Leisure \& Sport Research, Leeds Metropolitan University (now Leeds Beckett University), available at: www.leedsmet.ac.uk/ces/lssold/research/ countmein.pdf.

Coalter, F. (2013). Game Plan and The Spirit Level: the class ceiling and the limits of sports policy? International Journal of Sport Policy and Politics, 5(1), 3-19.

Collins, M.F. (2003). Sport and social exclusion. London: Routledge.

Cuypers, K., Krokstad, S., \& Holmen,T.L. (2012). Patterns of receptive and creative cultural activities and their association with perceived health, anxiety, depression and satisfaction with life among adults: the HUNT study, Norway. Journal of Epidemiology and Community Health, 66, 698-703.

De Botton, A. (2005). Status anxiety. London: Penguin.

Department for Culture, Media \& Sport (1999). Local cultural strategies: draft guidance for local authorities in England. London: DCMS.

Department of the Environment (1975). Sport and recreation, Cmnd, 6200. London: HMSO.

Dumazedier, J. (1974). Sociology of leisure. Amsterdam: Elsevier.

Economist (2012). True progressivism. 13 October, p. 14.

Elias, N., \& Dunning, E. (1986). Quest for excitement; sport and leisure in the civilizing process. Oxford; Basil Blackwell.

European Commission (2007). European cultural values: Special Eurobarometer 278/Wave 67. Brussels: European Commission.

European Commission (2009). Sport and physical activity :Special Eurobarometer 334/Wave 72.3. Brussels: European Commission.

Fisher, K., \& Robinson, J. (2010). Daily routines in 22 countries: diary evidence of average daily time spent in thirty activities. Technical Paper 2010-01, Oxford: Centre for Time Use Research, University of Oxford, available at: www.timeuse.org.

Frank, R. H (2005). Positional externalities cause large and preventable welfare losses. American Economic Review, 95(2), 137-45.

Frank, R. H. (2006). Taking libertarian concerns seriously: reply to Kashdan and Klein. Economic Journal Watch, 3(3), 435-51.

Friedman, M., \& Friedman, R. (1979). Free to choose. Harmondworth, UK: Penguin.

Goldthorpe, J.H. (2010). Analysing social inequality: a critique of two recent contributions from economics and epidemiology. European Sociological Review, 26(6), 731-44.

Goodin, R.E., Rice, J. M., Parpo, A., \& Eriksson, L. (2008). Discretionary time: a new measure of freedom. Cambridge: Cambridge University Press.

Gratton, C., Rowe, N., \& Veal, A.J. (2011). International comparisons of sport participation in European countries: an update of the COMPASS project. European Journal of Sport and Society, 8(1-2), 99-116.

Groningen University Conference Board (Annual). Total Economy Database. Groningen, Sweden: GUCB, available at: www.conference-board.org/data/economydatabase/.

Harmonised European Time-Use Survey (HETUS) (nd). Harmonised European Time-Use Survey website. Stockholm: Statistics Sweden: www.h2.scb.se/tus/tus/.

Haworth , J.T. (1997). Work, leisure and well-being. London: Routledge. 
Howard, D.R., \& Crompton, J.L. (1984). Who are the consumers of public park and recreation services? An analysis of the users and non-users of three municipal leisure service organizations. Journal of Park and Recreation Administration, 2(3), 33-48.

Inglehart, R., \& Baker, W.E. (2000). Modernization, cultural change, and the persistence of traditional values. American Sociological Review, 65(1), 19-51.

Jackson, E.L. (Ed.) (2006). Leisure and the quality of life: impacts on social, economic and cultural development: Hangzhou Consensus. Hangzhou, China: Zhejiang University Press/World Leisure Organisation.

Jump, P. (2010). Scholars reject further debate with ideologues. Times Higher Education, 19 August, online at: www.timeshighereducation.co.uk/news/scholars-reject-furtherdebate-with-ideologues/413094.article.

Kashdan, A., \& Klein, D.B. (2006). Assume the positional: comment on Robert Frank. Economic Journal Watch, 3(3), 412-34.

Lancee, B., \& Van de Werfhorst, H. (2011). Income inequality and participation: a comparison of 24 European countries. Amsterdam: Centre for Inequality Studies (available at: www.gini-research.org).

Lancee, B., \& Van de Werfhorst, H. (2012). Income inequality and participation: a comparison of 24 European countries. Social Science Research, 41, 1166-78.

Liu, Y-D. (2009). Sport and social inclusion: evidence from the performance of public leisure facilities. Social Indicators Research, 90(2), 325-37.

Lusted, J. (2013). Equality policies in sport: carrots, sticks and a retreat from the radical. Journal of Policy Research in Tourism, Leisure and Events, 6(1), 85-90.

Nichols, G. (2009). Inequality and positional consumption: a fresh insight into debates in leisure studies on time pressures on leisure and volunteering, choosing a work/life balance and the nature of the 'leisure' society. Journal of Policy Research in Tourism, Leisure and Events, 1(3), 270-75.

Nichols, G., \& Veal, A.J. (2013). Income inequality and volunteering: a transnational analysis. Presentation to the Australian and New Zealand Association for Leisure Studies biennial conference, Frankston, Vic., December.

Office for National Statistics (2005). Time use, 2005 edition: reference tables. London: ONS, available from: www.ons.gov.uk.

Oreskes, N., \& Conway, E.M. (2010). Merchants of doubt: how a handful of scientists obscured the truth on issues from tobacco smoke to global warming. London: Bloomsbury.

Organisation for Economic Cooperation and Development (OECD) (2011). An overview of growing income inequalities in OECD countries. Paris: OECD.

Outdoor Recreation Resources Review Commission (ORRRC) (1962). Participation in outdoor recreation: factors affecting demand among American adults. ORRRC Study Report 20. Washington, DC: ORRRC.

Parker, H., Aldridge, J., \& Measham, F. (1998). Illegal leisure: the normalization of adolescent recreational drug use. London: Routledge.

Piketty, T. 2014). Capital in the twenty-first century. Cambridge, MA: Harvard University Press.

Roberts, K. (2004). The leisure industries. Basingstoke, UK: Palgrave Macmillan.,

Roberts, K. (2013). Social class and leisure during recent recessions in Britain. Leisure Studies, online: http://dx.doi.org/10.1080/02614367.2013.855939.

Runciman, D. (2009). How messy it all is [Review of The Spirit Level]. London Review of Books, 31(20), 3-6.

Sanandaji, N., Malm, A., \& Sanandaji, T. (2010). The spirit illusion: a critical analysis of how "The Spirit Level' compares countries. London: Taxpayers' Alliance (available at: 
www.taxpayersalliance.com).

Saunders, P. (2010). Beware false prophets: equality, the good society and The Spirit Level. London: Policy Exchange (available at: www.policyexchange.org.uk).

Schor, J. (1998). The overspent American: why we want what we don't need. New York: Harper.

Skidelsky, R., \& Skidelsky, E. (2012). How much is enough? the love of money and the case for the good life. London: Allen Lane.

Snowdon, C. (2009). Velvet glove, iron fist: a history of anti-smoking. Ripon, UK: Little Dice.

Snowdon, C. (2010a). The Spirit Level delusion: fact-checking the left's new theory of everything. Ripon, UK: Democracy Institute/Little Dice (available at www.spiritlevel delusion. com).

Snowdon, C. (2010b). The Spirit Level response. London: Taxpayers' Alliance, available at: www.taxpayersalliance.com/home/2010/07/.

Snowdon, C. (2010c). The Spirit Level delusion: epilogue. Ripon, UK: Democracy Institute/ Little Dice, available at: www.spiritleveldelusion.com.

Sport England (2004). The equality standard: a framework for sport. London: Sport England.

Sport England (2013). Active people survey, April 2012-April 2013. London: Sport England, available at: www.sportengland.org/research/who-plays-sport/national-picture/who-playssport/.

Stiglitz, J.E. (2013). The price of inequality: how today's divided society endangers our future. New York: Norton.

Szalai, A. (Ed.) (1972). The use of time: daily activities of urban and suburban populations in twelve countries. The Hague: Mouton.

Szlendak, T., \& Karwacki, A. (2012). Do the Swedes really aspire to sense and the Portuguese to status? Cultural activity and income gap in the member states of the European Union. International Sociology, 27(6), 807-26.

Tóth, I.G. (2014). Revisiting grand narratives of growing inequalities: lessons from 30 country studies (pp. 11-47). In Nolan, B., Salverda, W., \& Cecchi, D. (Eds) Changing inequalities and societal impacts in rich countries: thirty countries' experiences. Oxford: Oxford University Press.

Veal, A.J. (2012). The leisure society II: the era of critique, 1980-2011. World Leisure Journal, 54(2), 99-140.

Veblen, T. (1899/1970). The theory of the leisure class. London, Allen and Unwin.

Wilkinson, R., \& Pickett, K. (2006). Income inequality and population health: a review and explanation of the evidence. Social Science and Medicine, 62, 1768-84.

Wilkinson, R., \& Pickett, K. (2009). The spirit level: why more equal societies almost always do better. London: Allen Lane.

Wilkinson, R., \& Pickett, K. (2010a). Professors Richard Wilkinson and Kate Pickett, authors of The Spirit Level, reply to critics. London: Equality Trust, available at $<$ www.equalitytrust.org.ul/sites/default/files/response-to-snowdon.pdf>

Wilkinson, R., \& Pickett, K. (2010b). The spirit level: why equality is better for everyone London: Penguin.

World Economic Forum (2014). Global risks 2014. Geneva: WEF, available at: www. weforum.org/risks. 


\section{Notes}

\footnotetext{
${ }^{\mathrm{i}}$ Wilson and Pickett also examined American states, which we do not consider here.

${ }^{\text {ii }}$ Coincidentally, Christopher Snowdon (2009) was one author who was sceptical about the tobacco-cancer link.

iii Wilkinson and Picket (2010: 223-5) mention the Bowles and Park paper to emphasise the significance of relative, as opposed to absolute, income, but do not treat working hours as one of their human well-being indicators.

${ }^{\text {iv }}$ A key difference between this presentation and Spirit Level diagrams is the position of Japan, which is clearly far from being the country with the most equal income distribution - a finding which was the focus of much discussion in The Spirit Level and commentaries (e.g. Goldthorpe, 2010). However, recent authoritative publications place Japan in the middle range of countries in terms of income distribution (OECD, 2011: 45; Tóth, 2014: 26).
} 